EPJ Web of Conferences 82, 01012 (2015)

DOI: $10.1051 /$ epjconf/20158201012

(C) Owned by the authors, published by EDP Sciences, 2015

\title{
Ignition of organic explosives by an electron beam
}

\author{
Georgy A. Ivanov ${ }^{1}$ and Alexander V. Khaneft ${ }^{1,2, a}$ \\ ${ }^{1}$ Kemerovo State University, 650043 Kemerovo, Russia \\ ${ }^{2}$ National Research Tomsk Polytechnic University, 634050 Tomsk, Russia
}

\begin{abstract}
A numerical simulation of the ignition of organic explosives (PETN, HMX, RDX, TATB) with an electron beam was performed. A criterion for the ignition of energetic materials with a melting point below the temperature of ignition is obtained. The results of numerical calculations of the critical energy density of the electron beam are consistent with the criterion of ignition. Calculations of the critical energy density of PETN ignition in good agreement with the experiment. The most sensitive is PETN and the most heat-resistant is TATB.
\end{abstract}

\section{Introduction}

Recently there has been a considerable increase in the number of papers on both experimental studies and numerical simulation of the conditions of explosive initiation by electron pulse [1-6]. It is caused by both the development of the new explosive initiation methods and scientific interest in defining the initiation mechanism in order to regulate the threshold energy of initiation purposefully.

The majority of the experiments on organic explosive initiation are done with PETN. The critical energy density of an electron beam $W^{*}$, which leads to the initiation of PETN in the area of the absorption of the electron beam, is $\sim 15 \mathrm{~J} / \mathrm{cm}^{2}$ at the initial energy of electrons $E_{0}=250 \mathrm{keV}$ and the time of delay $\sim 3.45 \mu$ s [1]. The energy, released in the area of electron beam absorption, is not enough for the detonation of the rest of the sample. At the current energy density the detonation of PETN takes place if there is a copper plate on the backside of the sample. The detonation spreads from the boundary "explosive - metal" to the area of electron beam absorption. In case of free surface, the detonation of the PETN compressed tablets takes place while the absorption of the electrons which energy density is $W_{D} \sim 60 \mathrm{~J} / \mathrm{cm}^{2}$ and initial energy is $E_{0}=450 \mathrm{keV}$. Monocrystals of PETN are destroyed [2]. It can be explained by the fact that the explosive can collapse before detonating if the time of ignition delay exceeds the time of occurrence of critically tensile thermoelastic stresses [7].

Nowadays there are three points of view on the mechanism of PETN initiation by the electron beam: the electric discharge model [2], the thermal model [1, 5] and the torch model [4]. The metal is known to attract electrons. Thus, if PETN detonation can be caused by electric breakdown then the direction of its propagation contradicts experimentally shown direction of detonation propagation when the copper plate is used. Paper [5] examines the thermal model of PETN initiation which has the system

\footnotetext{
${ }^{a}$ Corresponding author: khaneft@kemsu.ru
}

This is an Open Access article distributed under the terms of the Creative Commons Attribution License 4.0, which permits unrestricted use, distribution, and reproduction in any medium, provided the original work is properly cited. 
of coupled thermoelasticity equations as its basis. Paper [6] analyzes radiation-thermal mechanism of PETN initiation by the electron beam.

The objective of the current paper is to find out if the thermal model qualitatively describes the experimental data on PETN initiation by a broad electron beam ignoring thermoelastic stress and autocatalisys reaction. Besides, it would be quite interesting to carry out calculations and predict the threshold density of electron beam energy for initiation of RDX, HMX and TATB.

\section{Problem statement}

We analyze the thermal model of explosive initiation by the nanosecond electron beam taking into account the transformation of the explosive due to the first-order reaction. One-dimensional thermal conductivity equation, taking melting into consideration and the kinetic equation of first-order chemical reaction are set as:

$$
\begin{aligned}
\rho\left[c+H_{f} \delta\left(T-T_{f}\right)\right] \frac{\partial T}{\partial t} & =\lambda \frac{\partial^{2} T}{\partial x^{2}}+\frac{\Lambda(x)}{R_{e f}} I(t)+\rho Q \frac{d \eta}{d t}, \\
\frac{d \eta}{d t} & =k_{1}(1-\eta) .
\end{aligned}
$$

with the following initial and boundary conditions

$$
\eta(x, 0)=0, \quad-\lambda \frac{\partial T(0, t)}{\partial x}=0, \quad-\lambda \frac{\partial T(h, t)}{\partial x}=0 .
$$

Here $H_{f}$ is the latent heat of melting; $\delta\left(T-T_{f}\right)$ is the delta-function; $\lambda, c$ are thermal conductivity coefficient and specific heat; $\rho$ is density; $Q$ are the heat of the reaction per the mass unit of the material; $R_{e f}$ is the effective track length of electrons; $I(t)$ is the energy flux density of the electron beam; $\Lambda(x)$ is the distribution of absorbed energy density of the electron beam along the crystal; $h$ is the thickness of the sample; $\eta$ is the conversion level of the explosive.

First-order reaction rate constant is determined as

$$
k_{1}=Z \exp (-E / R T),
$$

where $Z$ is the frequency factor; $E$ is the activation energy of chemical reaction rate; $R$ is the universal gas constant. The dependence of electron beam intensity on time is given by

$$
I(t)=j(0, t) U_{0}(t)=\frac{W}{6 \tau_{m}}\left(4 t / \tau_{m}\right)^{4} \exp \left(-4 t / \tau_{m}\right),
$$

where $j(0, t)$ is the current density of electron at the entrance to the solid; $U_{0}(t)$ is accelerating stress of the electron beam generator; $W$ is the energy density of the electron beam . The experimental curve of the density distribution of absorbed energy for PETN [8] is satisfactorily described by equation [5, 6]:

$$
W_{a b}(\xi) / W_{a b}\left(\xi_{m}\right)=\Lambda(\xi)=0.7+1.57 \xi-2.31 \xi^{2}+0.61 \xi,
$$

where $\xi=x / R_{e f}$. If $\xi=\xi_{m}$, the function is $\Lambda\left(\xi_{m}\right)=1$. If $\xi \geq \xi_{e x}=1.44$, the function is $\Lambda(\xi)=0$ and the integral

$$
\int_{0}^{1.44} \Lambda(\xi) d \xi=1 .
$$

It is believed for RDX, HMX and TATB that the distribution of electron beam absorbed energy correlates with Eq. (4). The extrapolated track length of electrons, which initial energy is $E_{0}=250 \mathrm{keV}$ for RDX, HMX and TATB is calculated by the empirical formula, introduced in the 
article [8]:

$$
R_{e x}=\frac{a_{1}}{\rho}\left[\frac{1}{a_{2}} \ln \left(1+a_{2} e_{0}\right)-\frac{a_{3} e_{0}}{1+a_{4} e_{0}^{a_{5}}}\right], \quad \mathrm{cm} .
$$

Here $\rho$ is the density of the medium, measured in $\mathrm{g} / \mathrm{cm}^{3} ; e_{0}=E_{0} / m c^{2}\left(m c^{2}\right.$ is the rest energy of an electron, equal to $511 \mathrm{keV}$ ); constants

$$
\begin{gathered}
a_{1}=0.2335 A_{e f} / Z_{e f}^{1.09}, \quad a_{2}=1.8 \cdot 10^{-4} Z_{e f}, \\
a_{3}=0.989-3 \cdot 10^{-4} Z_{e f}, \quad a_{4}=1.468-1.18 \cdot 10^{-2} Z_{e f}, \\
a_{5}=1.232 / Z_{e f}^{1,209},
\end{gathered}
$$

where $A_{e f}$ is effective atomic mass; $Z_{e f}$ is effective atomic number. Effective atomic mass and effective atomic number are determined by formulas

$$
\begin{gathered}
Z_{e f}=\sum_{i=1}^{n} f_{i} Z_{i}, \quad A_{e f}=\frac{Z_{e f}}{(Z / A)_{e f}}, \\
(Z / A)_{e f}=\sum_{i=1}^{n}\left(f_{i} Z_{i} / A_{i}\right), \quad f_{i}=A_{i} / \sum_{i=1}^{n} A_{i} .
\end{gathered}
$$

Here $Z_{i}, A_{i}$ are atomic number and atomic mass of $i$ element; $f_{i}$ is its weight fraction; $n$ is the number of weight fractions. The estimation of $R_{e f}$ for PETN using formula (5) at $\xi_{e x}=1.44$ shows that calculated value is $14 \%$ less than $R_{e f}$, obtained while processing experiment results. That's why the calculated values of $R_{e f}$ for simulation of RDX, HMX and TATB initiation by the electron beam are increased by $14 \%$ correspondingly.

\section{The criterion for the ignition of the explosives the election beam}

One-dimensional criterion for ignition of the explosive by the laser beam of small width is obtained in paper [9]. However, if the track length of electrons in a solid is commensurate with the beam radius $r_{0}$, criterion [9] requires radial heat removal to be taken into account as it is done in case of initiation of the explosives by the laser pulse in paper [10]. Besides, if the melting temperature is lower than the ignition temperature of explosives, the heat of melting is to be considered in critical energy density. It can be easily shown by using approach [10] that in case of Gaussian energy distribution along the beam section the current criterion is given by:

$$
\begin{aligned}
\rho Q Z \exp \left(-\frac{E}{R T_{m}}\right) & =\frac{\lambda \Delta T_{m}}{R_{e f}^{2}}\left(-\frac{1}{\Lambda_{m}} \frac{\partial^{2} \Lambda_{m}}{\partial \xi^{2}}+\frac{4}{F(\gamma)} \frac{R_{e f}^{2}}{r_{0}^{2}}\right), \\
W^{*} & =\rho R_{e f}\left(c \Delta T_{m}+H_{f}\right),
\end{aligned}
$$

where $\Delta T_{m}=T_{m}-T_{0}$ is the critical temperature at the maximum of electron beam absorption.

\section{Results and discussion}

The system of Eqs. (1), (2) with initial and boundary conditions (3) is solved numerically using an implicit difference scheme. The difference heat conductivity equations are solved by the sweep method. The calculations are carried out at the following kinetic and thermal physic parameters of 


\section{EPJ Web of Conferences}

Table 1. The critical energy densities of the ignition of explosives by the electron pulse.

\begin{tabular}{|l|l|l|l|l|}
\hline Explosive & PETN & RDX & HMX & TATB \\
\hline$W^{*}, \mathrm{~J} / \mathrm{cm}^{2}$ (criterion) & 14.41 & 20.64 & 21.14 & 29.44 \\
\hline$W^{*}, \mathrm{~J} / \mathrm{cm}^{2}$ (calculation) & 15 & 21.5 & 22 & 30.5 \\
\hline
\end{tabular}

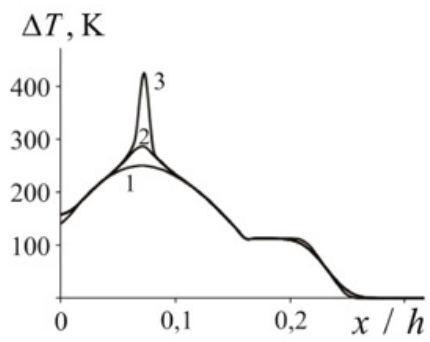

Figure 1. The dynamics of temperature distribution in the area of electron beam absorption at PETN ignition: $t=10^{-4}(1), 6 \cdot 10^{-4}(2)$ and $6.42 \cdot 10^{-4}(3) \mathrm{s}$ at $W=15.5 \mathrm{~J} / \mathrm{cm}^{2}(h=1 \mathrm{~mm})$.

the explosive: PETN $-E=196.6 \mathrm{~kJ} / \mathrm{mol}, Z=6.3 \cdot 10^{19} \mathrm{~s}^{-1}, Q=1.26 \mathrm{MJ} / \mathrm{kg}, \lambda=0.25 \mathrm{~W} /(\mathrm{m} \cdot \mathrm{K})$, $T_{f}=413 \mathrm{~K}[11], c=1255 \mathrm{~J} /(\mathrm{kg} \cdot \mathrm{K})[12], \rho=1.77 \cdot 10^{3} \mathrm{~kg} / \mathrm{m}^{3}[13], H_{f}=193 \mathrm{~kJ} / \mathrm{kg}$ [14]; RDX $E=197.3 \mathrm{~kJ} / \mathrm{mol}, Z=2.02 \cdot 10^{18} \mathrm{~s}^{-1}, Q=2.1 \mathrm{MJ} / \mathrm{kg}, \lambda=0.105 \mathrm{~W} /(\mathrm{m} \cdot \mathrm{K}), T_{f}=476 \mathrm{~K}[11], c=$ $1000 \mathrm{~J} /(\mathrm{kg} \cdot \mathrm{K})[13], \rho=1.82 \cdot 10^{3} \mathrm{~kg} / \mathrm{m}^{3}$ [15], $H_{f}=235.5 \mathrm{~kJ} / \mathrm{kg}$ [14]; HMX $-E=220.8 \mathrm{~kJ} / \mathrm{mol}$, $Z=5.0 \cdot 10^{19} \mathrm{~s}^{-1}, Q=2.1 \mathrm{MJ} / \mathrm{kg}, \lambda=0.293 \mathrm{~W} /(\mathrm{m} \cdot \mathrm{K}), T_{f}=558 \mathrm{~K}[11], c=1250 \mathrm{~J} /(\mathrm{kg} \cdot \mathrm{K})[16]$, $\rho=1.9 \cdot 10^{3} \mathrm{~kg} / \mathrm{m}^{3}[15], H_{f}=192.46 \mathrm{~kJ} / \mathrm{kg}[17]$; TATB $-E=250.9 \mathrm{~kJ} / \mathrm{mol}, Z=3.8 \cdot 10^{19} \mathrm{~s}^{-1}, Q=$ $2.51 \mathrm{MJ} / \mathrm{kg}, \lambda=0.418 \mathrm{~W} /(\mathrm{m} \cdot \mathrm{K}), T_{f}=623 \mathrm{~K}[11], c=1250 \mathrm{~J} /(\mathrm{kg} \cdot \mathrm{K}), \rho=1.93 \cdot 10^{3} \mathrm{~kg} / \mathrm{m}^{3}[13]$, $H_{f}=192.46 \mathrm{~kJ} / \mathrm{kg}$.

The heat of melting for TATB is determined by empirical formula

$$
H_{f} / T_{f} \approx C,
$$

where $C \approx 0.43 \mathrm{~kJ} /(\mathrm{kg} \cdot \mathrm{K}) . C$ is estimated by averaging $H_{f} / T_{f}$ for PETN, RDX and HMX.

The calculated values for the critical density energy $W^{*}$ of the explosive ignition electron beam at the threshold are in good agreement with the criterion of ignition (9) at $r_{0} \gg R_{e f}$. The table shows the critical energy densities of the explosive ignition by the electron pulse. According to Table, the most sensitive to the initiation by the electron pulse is PETN and the most heat-resistant is TATB.

Calculations indicate that the most sensitive to the initiation by the electron pulse is PETN and the most heat-resistant is TATB. Some calculation results are presented in Fig. 1-Fig. 6. Figure 1 and Fig. 3 show the calculation results of temperature distribution in PETN and TATB in the absorption area of the electron beam with pulse duration $\tau_{i}=15 \mathrm{~ns}$ and energy $E_{0}=250 \mathrm{keV}$. "Shelves" occur on the curves (1)-(3) due to the melting of the explosive. Figures 2 and 4 indicate the calculation results of temperature dependence on time $\Delta T_{m}$ at the maximum of electron beam absorption near the initiation threshold in PETN and TATB. The appearance of "ledges" on these curves is caused by the melting of explosive. The calculation results of temperature distribution dynamics for HMX and RDX are similar.

Figure 5 shows the calculation results of delay time for PETN, HMX, RDX and TATB initiation by the pulsed beam. TATB has the longest delay time and PETN has the shortest one. The delay time is calculated numerically considering that

$$
\left.\frac{d \Delta T_{m}}{d t}\right|_{t=t^{*}} \rightarrow \infty
$$




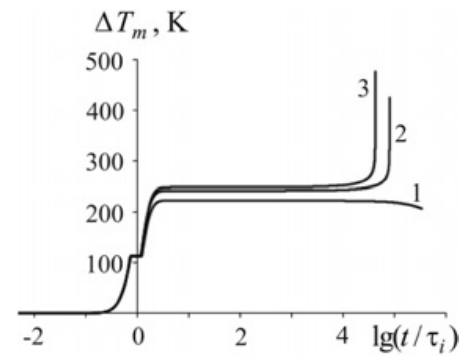

Figure 2. The dependence of temperature on time at the maximum of electron beam absorption in PETN, if $W=14.5(1), 15.25(2)$ and $15.5 \mathrm{~J} / \mathrm{cm}^{2}(3)$.

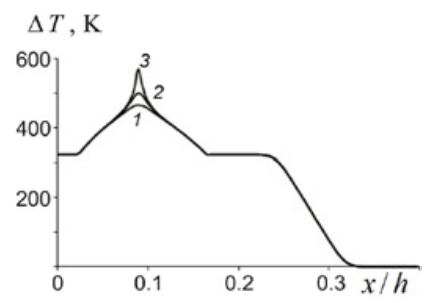

Figure 3. The dynamics of temperature distribution in the area of electron beam absorption at TATB ignition: $t=1.6 \cdot 10^{-4}(1), 1.9 \cdot 10^{-4}(2)$ and $1.97 \cdot 10^{-4}(3) \mathrm{s}$, if $W=30 \mathrm{~J} / \mathrm{cm}^{2}$.

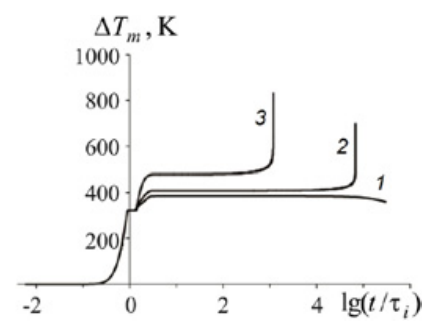

Figure 4. The dependence of temperature change on time at the maximum of electron beam absorption in TATB, if $W=28(1), 29(2), 32(3) \mathrm{J} / \mathrm{cm}^{2}$.

The calculated value of delay time $t^{*}$ for PETN exceeds the experimental one by 2.5 factors of PETN. Partly it can be explained by the fact that the experiments on the initiation of explosives by the electron or laser pulses are usually carried out a bit higher than the ignition threshold. We obtain no experimental data on $t^{*}$ for the electron beam energy $W_{D} \sim 60 \mathrm{~J} / \mathrm{cm}^{2}$, which leads to the detonation. Critical energy density of ignition of the electron beam is about twice as little as the energy density while detonating [2] (Fig. 6). Thus, "classical thermal explosion" does not allow complete describing of the experiments on PETN initiation by the electron beam.

This experiment is well explained if thermoelastic stresses, which are known to affect the activation energy of chemical reaction [5], and radiation-thermal mechanism of initiation [6] is taken into account. It should be noted, that the exothermic reaction makes a major contribution to the process of the ignition of the explosive by the nanosecond electron beam. 


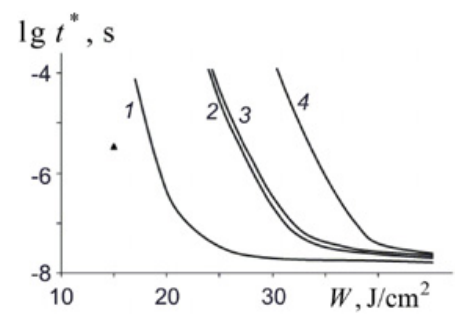

Figure 5. The dependence of the delay time of the ignition of the explosives on the density energy of electron pulse (lines - calculation: 1 - PETN, 2 - HMX, 3 - RDX, 4 - TATB, $\Delta$ - experiment [1], $E_{0}=250 \mathrm{keV}$ ).

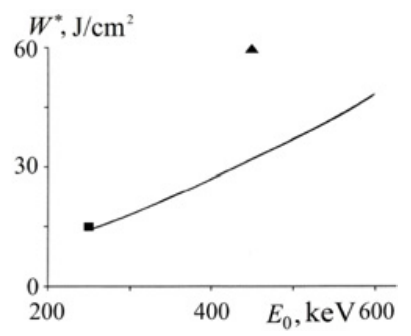

Figure 6. The dependence of $W^{*}$ of PETN initiation on the initial energy of electrons in the beam: line - calculation on criterion; - experiment [1]; $\boldsymbol{\Delta}$ - threshold energy of PETN detonation [2].

We estimate the pressure of the plasma, formed in the area of energy release while the detonation of PETN, using the formula given in paper [18]:

$$
P=\left(\gamma_{e f}-1\right) w
$$

where $\gamma_{e f}=1.2$ is the ration of specific heat capacity of the solid and plasma; $w$ is the volume density of absorbed energy. The volume density of absorbed energy for the explosives is determined by a formula:

$$
w=\rho\left(Q-H_{f}\right)+W_{D} / \Delta z_{1} .
$$

Here $\Delta z_{1}$ is the width of the reaction zone, defined as

$$
\Delta z_{1}=R_{e f}\left(-\frac{2 R T_{m}}{E} \cdot \frac{T_{m} \Lambda_{m}}{\Delta T_{m} \Lambda_{m}^{\prime \prime}(1+\gamma)}\right)^{1 / 2} .
$$

If $W_{D}=60 \mathrm{~J} / \mathrm{cm}^{2}, R_{e f}=415.0 \cdot 10^{-4} \mathrm{~cm}, E_{0}=450 \mathrm{keV}$ and $\Delta z_{1} \approx 76 \cdot 10^{-4} \mathrm{~cm}$, we have $P \approx$ $1.96 \mathrm{GPa}$. The obtained value of pressure in detonation wave for PETN is quite reasonable. According to paper [19], if detonation is excited by an impact, then $P \sim 1.5 \mathrm{GPa}$. Maybe, if there is no copper plate on the backside of the sample, PETN doesn't detonate at $W=15 \mathrm{~J} / \mathrm{cm}^{2}$ due to the gas-dynamic relieving of the sample, because in this case energy is released near the surface.

\section{Conclusions}

1. Common dependency of organic explosives (PETN, RDX, HMX and TATB) ignition established. Most sensitive to the initiation by an electron pulse is PETN, and the most heat-resistant is TATB.

2. Calculations favor the thermal initiation mechanism of PETN by an electron pulse of a nanosecond duration. 


\section{References}

[1] B.P. Aduev, G.M. Belokurov, S.S. Grechin, V.N. Shvaiko, Izv. Vyssh. Uchebn. Zaved., Fiz. 50, 3 (2007) [in Russian]

[2] V.I. Oleshko, V.I., Korepanov, V.M. Lisitsyn, A.S. Skripin, V.P. Tsipilev, Technical physics letters 38, 415 (2012) [in Russian]

[3] V.I. Oleshko, V.P. Tsipilev, V.V. Lysyk, A.V. Razin, V.E. Zarko, P.I. Kalmykov, Izv. Vyssh. Uchebn. Zaved., Fiz. 55, 158 (2012) [in Russian]

[4] V.A. Morozov, G.G. Savencov, V.A. Bragin, V.M. Kats, A.A. Lukin, Technical Physics 57, 706 (2012)

[5] A.V. Khaneft, E.V. Duginov, G.A. Ivanov, Khimicheskay Fizika Mezoskopiya 14, 28 (2012) [in Russian]

[6] G.A. Ivanov, A.V. Khaneft, Russ. J. Phys. Chem. B 7, 741 (2013)

[7] A.V. Khaneft, E.V. Duginov, Eurasian Physical Technical Journal 5, 31 (2008)

[8] Tatsuo Tabata and Rinsuke Ito, Nuclear Science and Engineering 53, 226 (1974)

[9] A.V. Khaneft, Chem. Phys. Reports 17, 1573 (1998)

[10] A.V. Khaneft, Chem. Phys. Reports 17, 1889 (1998)

[11] L.P. Orlenko, Explosion Physics (Nauka, Moscow, 2002) [in Russian]

[12] A.V. Belyaev, V.K. Bobolev, A.I. Korotkov, A.A. Sulimov, S.V. Chuiko, Transition of condensed systems from ignition to explosion (Nauka, Moscow, 1973) [in Russian]

[13] A. Borisov, Detonation and Explosives, (Mir, Moscow, 1981) [in Russian]

[14] F.A. Baum, A.S. Derzhavec, N.N. Sanasaryan, Thermoresistant explosives and their effect in deep wells (Nedra, Moscow, 1969) [in Russian]

[15] R. Shall, Physics of a detonation, in "Physics of high energy density" (Mir, Moscow, 1974) [in Russian]

[16] I.G. Assovskiy, Physics of combustion and interior ballistics (Nauka, Moscow, 2005) [in Russian]

[17] A. Strunin, L.I. Nikolaeva, G.B. Manelis, Khimicheskaya Fizika, 29, 63-70 (2010) [in Russian]

[18] S.S. Batsanov, B.A. Demidov, L.I. Rudakov, JETP Letters 30, 575 (1979)

[19] V.A. Morozov, Yu.V. Petrov, G.G. Savenkov, Dokl. Ross. Akad. Nauk 445, 286 (2012) [in Russian] 